\title{
EDITORIAL
}

\section{Use of Measurement Uncertainty in Compliance Assessment with Regulatory Limits}

\section{Elcio Cruz de Oliveira}

Professor of the Postgraduate Programme in Metrology Metrology for Quality and Innovation, Pontifical Catholic University of Rio de Janeiro - Rio de Janeiro, RJ, Brazil

Technical Consultant, Petrobras Transporte S.A. - TRANSPETRO $\triangle$ Rio de Janeiro, RJ, Brazil

Measurement results, especially in Analytical Chemistry, must be presented in order to guarantee reliability, so that the information can be evaluated and compared with values provided in standards or regulatory limits. These measurement processes must be unambiguous so that, when reproduced anywhere in the world, metrologically compatible results are achieved.

To use a result and decide whether it indicates conformity or non-conformity with a specification, the recent literature recommends considering measurement uncertainty as the main indicator of the quality of any experimental result [1].

I highlight the importance of conformity assessment vis-à-vis the concepts of decision rules. Such rules are based on the level of acceptable probability for a wrong decision on the acceptance or rejection of a product, based on the measurement result accompanied by its uncertainty, reference risk (consumer, producer or shared), specification limits and guard band for conformity assessment against regulatory limits.

The greater the value of measurement uncertainty (sampling uncertainty plus analytical uncertainty) [2], the greater the proportion of samples that will be judged incorrectly. However, the lower the value of this variability, the greater the cost of the analysis. Thus, ideally, the quality of the measurement process should have an uncertainty value in order to balance the costs of analysis and incorrect decisions.

For instance, in the area of oil and gas, Brazil's National Agency of Petroleum, Natural Gas and Biofuels (ANP) regulates the quality of fuels. In the case of commercial gasoline, the upper limit for the specification of the sulfur mass fraction is $50 \mathrm{mg} \mathrm{kg}^{-1}$. Considering a typical result of this critical parameter analyzed by ultraviolet fluorescence as $45.5 \mathrm{mg} \mathrm{kg}^{-1}$, for a measurement uncertainty of $5 \mathrm{mg} \mathrm{kg}^{-1}(\mathrm{k}=2 ; 95.45 \%)$ and a risk of $5 \%$ for the consumer, is this item considered to conform or not?

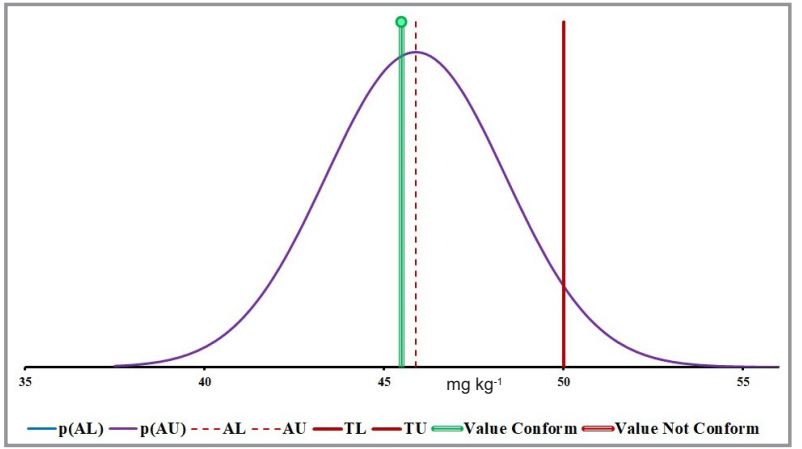

Conformity assessment
$p(A L)$ - probability density at the lower acceptance limit $p(A U)$ - probability density at the upper acceptance limit

$\mathrm{AL}$ - Lower acceptance limit

AU - Upper acceptance limit

TL - Lower tolerance limit

TU - Upper tolerance limit

Final conformity assessment: This item is conform to an effective Consumer's Risk of $5 \%$. 
Finally, in order to leave no doubt concerning the decision rules, a clear and unequivocal method of decision-making should be stated, including the parameters mentioned above in detail. For advanced approaches, I recommend including repeated measurements, the detection and treatment of outliers and multivariate acceptance limits [3].

I am completely confident that BrJAC is in the correct way in order to become a renowned journal, since our publications are shedding light on the importance of Analytical Chemistry related to industrial activities, which can no longer be pushed aside. This issue highlights quality control and the optimization of industrial processes; I invite you to send us manuscripts correlating analytical data to regulatory limits and specifications. Let's think outside the box and understand that this approach continues be Analytical Chemistry!

\section{REFERENCES}

1. Ellison, S. L. R.; Williams, A. (Eds). Eurachem/CITAC guide: Use of uncertainty information in compliance assessment. First Edition, Eurachem, 2007.

2. Ramsey, M. H.; Ellison, S. L. R.; Rostron, P. (Eds.) Eurachem/EUROLAB/ CITAC/Nordtest/AMC Guide: Measurement uncertainty arising from sampling: a guide to methods and approaches. Second Edition, Eurachem, 2019.

3. de Oliveira, E. C.; Lourenço, F. R. Chemosphere, 2021, 263, 128265 (https://doi.org/10.1016/j. chemosphere.2020.128265).

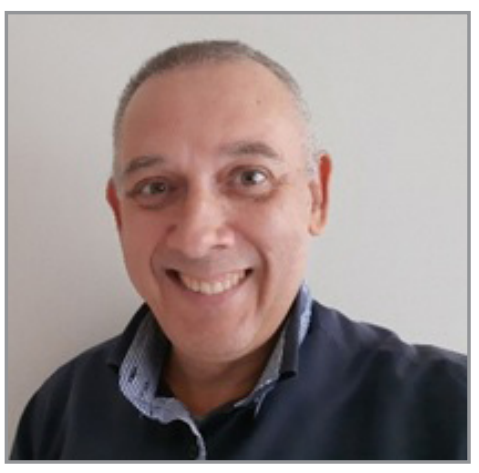

Elcio Cruz de Oliveira has a degree in Chemistry from the Rio de Janeiro State University (1990), a Master's degree in Metrology from the Pontifical Catholic University of Rio de Janeiro (2001) and a Doctoral degree in Analytical Chemistry from the Rio de Janeiro Federal University (2008). He is currently a Professor of the Postgraduate Programme in Metrology, Metrology for Quality and Innovation, Pontifical Catholic University of Rio de Janeiro, and a Researcher in Petrobras Transporte S.A. - TRANSPETRO. His research activities include all areas of chemical metrology, but mainly related to the oil \& gas industry. 